\title{
Educação inclusiva: um estudo de caso sobre o trabalho docente no Ensino Fundamental I
}

Tauane Andrade de Souza

Mestranda em Educação Escolar. UNESP - Universidade Estadual Paulista. Faculdade de Ciências e Letras - Pós-graduação em Educação Escolar. Araraquara - SP - Brasil. 14800-901 - tauaneandrade3@hotmail.com

\section{Eliane Aparecida Piza Candido}

Mestranda em Educação Escolar. UNESP - Universidade Estadual Paulista. Faculdade de Ciências e Letras - Pós-graduação em Educação Escolar. Araraquara - SP - Brasil. 14800-901 - pizaeliane@hotmail.com

\section{Relma Urel Carbone Carneiro}

Docente do Departamento de Psicologia da Educação e do Programa de PósGraduação em Educação Escolar. UNESP - Universidade Estadual Paulista. Faculdade de Ciências e Letras - Pós-graduação em Educação Escolar. Araraquara - SP - Brasil. 14800-901 - relmaurel@fclar.unesp.br 


\section{Resumo}

Este estudo de caso teve como objetivo apresentar e analisar as experiências vividas por uma professora do Ensino Fundamental I, que atuava com estudante com mielomeningocele, acerca de suas concepções sobre o ser professor, a inclusão deste estudante no ensino regular, o apoio da equipe gestora e adaptações físicas e/ou curriculares e a participação da família. Para isso, a coleta de dados foi realizada através de um questionário via e-mail com doze questões. As respostas foram analisadas e tabuladas por eixos temáticos, o que deixou evidente a cautela da professora quanto ao desenvolvimento do trabalho pedagógico visando à inclusão de seus alunos. Os resultados evidenciam a importância do comprometimento da equipe gestora com a inclusão, de modo a facilitar o trabalho do professor visando o desenvolvimento do estudante. Propomos assim, para a efetivação de uma escola inclusiva, formação, participação e investimento de todo o sistema educacional.

Palavras-chave: Educação Inclusiva. Trabalho Docente. Ensino Fundamental I.

\section{Abstract}

This case study aimed to present and analyze the experiences of a primary school teacher, who worked with a student with myelomeningocele, about her conceptions about being a teacher, the inclusion of this student on regular education, the support of the management team and physical and/or curricular adaptations activities and family participation. Therefore, the data collect was performed through an questionnaire sent by e-mail with twelve questions. The answers were analyzed and tabulated by thematic axes, which makes evident the teacher's attention regarding the development of the pedagogical work aiming the inclusion of its students. The results evidenced the importance of the management team with the inclusion, in order to facilitate the work of the teacher aiming the development of the student. Thus we propose, for the effectiveness of an inclusive school, formation, participation and investment of the entire educational system.

Keywords: Inclusive Education. Teaching Work. Elementary School I. 


\section{Introdução}

A discussão sobre uma Educação Inclusiva, capaz de oferecer um ensino de qualidade a todos os cidadãos, sem distinção de nenhuma ordem, de forma acessível e permanente, é uma realidade relativamente nova em nosso país.

O Estado sempre atrelou as políticas educacionais brasileiras ao seu interesse. Durante o período monárquico, as oligarquias necessitavam de mão-de-obra, assim o Estado não tinha interesse na educação. Somente em 1920, devido às mudanças na economia mundial, o governo federal começou a estruturar o sistema educacional por todo o país, pois para trabalhar nas indústrias era necessário qualificar mão-de-obra. Getúlio Vargas assume o governo provisório em 1930 e cria o Ministério da Educação. Em 1932 liderado por Anísio Teixeira e vários intelectuais surge o movimento Escola Nova que propôs uma reforma educacional com criação de escolas públicas gratuitas, laicas e obrigatórias para todos. Em 1934 foi criado o Plano Nacional da Educação que instituia a obrigatoriedade e gratuidade do ensino primário e a fiscalização dos estabelecimentos de ensino público e privado pelos Estados. (GHIRALDELLI JÚNIOR, 1991).

A partir de então, muitas mudanças vêm ocorrendo em nosso sistema educacional. A lei no 12.796, de 04 de abril de 2013 que estabelece as diretrizes e bases da educação nacional, dispõe sobre a formação dos profissionais da educação e dá outras providências, estabelece que a educação básica tornou-se obrigatória e gratuita dos 4 (quatro) aos 17 (dezessete) anos de idade. Desta forma a Educação Infantil passa a fazer parte da Educação Básica.

Ainda retratando a Educação Básica, é importante descrever um pouco da história da Educação Especial no Brasil, que teve início na época do Império, com o Imperial Instituto dos Meninos Cegos, em 1854, e o Instituto dos Surdos Mudos, em 1857, ambos no Rio de Janeiro (FIGUEIRA, Emílio. 2008), no entanto, não havia nenhuma lei que regulamentasse esse ensino. Somente em 1961, o atendimento educacional às pessoas com deficiência passa a ser fundamentado pelas disposições da Lei de Diretrizes e Bases da Educação Nacional - LDBEN, Lei no 4.024/61, dizendo que "excepcionais" têm direito à educação. Em 1971 a Lei no 5.692/71, que altera a LDBEN de 1961, ao definir "tratamento especial" para os estudantes com "deficiências físicas, mentais, os que se encontram em atraso considerável quanto à idade regular de 
matrícula e os superdotados”, não promove a organização de um sistema de ensino capaz de atender aos estudantes com deficiência, altas habilidades/superdotação, e acaba reforçando o encaminhamento desses estudantes para as classes e escolas especiais. Apenas em 1996 com a Lei de Diretrizes e Bases da Educação Nacional, Lei no 9.394/96, no artigo 59, preconizou-se que os sistemas de ensino devem assegurar a esses estudantes currículo, métodos, recursos e organização específicos para atender às suas necessidades; assegurando a terminalidade específica àqueles que não atingiram o nível exigido para a conclusão do ensino fundamental, em virtude de suas deficiências; e assegura a aceleração de estudos aos superdotados para conclusão do programa escolar.

Nesta linha de mudança de paradigma objetivando uma escola para todos, o documento Política Nacional de Educação Especial na Perspectiva da Educação Inclusiva (BRASIL, 2008) estabelece o objetivo de acesso, participação e aprendizagem dos estudantes com deficiência, transtornos globais de desenvolvimento e altas habilidades/superdotação, definidos como público alvo da Educação Especial, nas escolas regulares, orientando os sistemas de ensino para promover respostas às necessidades educacionais de cada estudante.

Mais recentemente, em 2015, foi promulgada a LEI No 13.146 que institui a Lei Brasileira de Inclusão da Pessoa com Deficiência (Estatuto da Pessoa com Deficiência). Um importante avanço que traz em seu texto a autonomia e a capacidade desses cidadãos para exercerem atos da vida civil em condições de equidade perante a sociedade.

Apesar das recentes conquistas obtidas para o público alvo da Educação Especial - PAEE, referentes ao aspecto educacional, ainda carecemos de maior regulamentação de leis e do estabelecimento de Políticas Públicas para esse público, capazes de garantir mudanças efetivas no processo de escolarização dos mesmos, de forma a garantir acesso, permanência e sucesso acadêmico, de acordo com as possibilidades de cada um, em ambientes comuns.

A inclusão escolar de estudantes PAEE vem acontecendo de maneira progressiva em nossas escolas e muitas questões se apresentam sobre a efetividade desse processo, uma vez que essa prática apresenta muitos desafios, por ser relativamente nova, em várias áreas como formação de professores e de toda equipe escolar, acessibilidade física e pedagógica, recursos, entre outras. 
Diante desta realidade e da necessidade de investigação sobre esse processo, para análise do momento que vivemos e da produção de conhecimento sobre a inclusão de estudantes PAEE em escolas comuns, realizamos um estudo de caso através da aplicação de um questionário com uma professora do Ensino Fundamental I, que possuía um estudante com mielomeningocele, com o objetivo de apresentar e analisar as experiências vividas por ela no dia a dia, suscitando uma reflexão sobre esse processo.

\section{Método}

Essa pesquisa trata-se de um estudo de caso, que segundo (STAKE, 1995, p. $\mathrm{XI}$ ) "é o estudo da particularidade e da complexidade de um caso singular, levando a entender sua atividade dentro de importantes circunstâncias" tendo como cerne oferecer informações sobre um indivíduo, comunidade, instituição, etc., sendo neste caso a professora que se propõe a contribuir apresentando a atual situação de trabalho diante de um estudante com deficiência.

A professora participante atua na rede privada de ensino e foi solicitada para participar da pesquisa por atender os seguintes critérios: atuar como docente do Ensino Fundamental I e ter matriculado em sua sala de aula um estudante PAEE. A participante tem cinquenta anos de idade e atua na rede de ensino há vinte cinco anos. Se formou no magistério em 1988, e no curso de licenciatura em Pedagogia em 2001. Visando aprimoramento profissional cursou uma especialização em Psicopedagogia que concluiu em 2003. Relatando um pouco de sua história profissional, ela atuou durante três anos no Centro de Educação e Recreação - CER, em Araraquara, como agente educacional e um ano como professora de escolas estaduais do Estado de São Paulo. Atualmente ela atua no $3^{\circ}$ ano do Ensino Fundamental de uma escola privada de Araraquara que fica a cerca de 280 quilômetros da cidade de São Paulo, capital do Estado.

A professora ministra aula para um estudante com mielomeningocele, que trata-se de um defeito congênito da coluna e medula espinhal resultante do fechamento incompleto durante a $4^{a}$ semana de gestação, onde as meninges, a medula e as raízes nervosas estão expostas. O comprometimento neurológico na mielomeningocele é comum, incluindo alguns sinais e sintomas: fraqueza muscular das pernas (às vezes envolvendo paralisia), incontinência urinária e problemas intestinais, insensibilidade 
parcial ou total, convulsões, problemas ortopédicos (como pés deformados, quadris irregulares), escoliose e hidrocefalia (BIZZI, J. W. J.; MACHADO, A., 2012).

O processo educativo não se completa apenas com professor e aluno, o meio onde a interação acontece faz parte deste processo e a escolha da escola onde esta professora atua se deu pela sua história e comprometimento com a educação, sendo esta componente de uma rede de ensino privada do Estado de São Paulo, fundada em 1946 na capital paulista. Em Araraquara ela existe há trinta e sete anos, contando com o registro no Relatório Estatístico Mensal (REM) referente ao mês de Agosto de 2017, a escola conta 480 alunos matriculados do $1^{\circ}$ ao $5^{\circ}$ ano do Ensino Fundamental no ensino integral, 388 alunos matriculados do $6^{\circ}$ ao $9^{\circ}$ ano, também do Ensino Fundamental, porém ensino parcial (manhã) e 271 alunos matriculados no $1^{\circ}$ ao $3^{\circ}$ ano do Ensino Médio ensino parcial (tarde), totalizando 1139 alunos no total. Como ensino fundamental anos iniciais ( $1^{\circ}$ ao $5^{\circ}$ ano) nesta unidade funciona em período integral, exige-se que os alunos façam parte de suas refeições na escola.

O processo de inclusão torna-se evidente neste momento, pois além de fornecer toda a alimentação aos seus alunos, possui refeições diferenciadas a partir de cada restrição alimentar da criança, seja em relação ao sal, ao açúcar, ao corante, ao glúten, à lactose, etc., tudo é diferenciado a partir da necessidade. Além disso, na unidade há uma nutricionista, que prescreve os cardápios com alimentos saudáveis e balanceados para os alunos. Na unidade não há serviço especializado em Educação Especial, portanto não há AEE, quem ajuda as professoras em sala de aula são os estagiários. Há muitos estagiários, permanecendo um em cada sala que há alunos com deficiência.

\section{Procedimento de coleta de dados}

A coleta de dados foi realizada via e-mail. Dúvidas posteriores foram sanadas pessoalmente. Esse procedimento foi empregado devido à falta de tempo da professora, que trabalha em período integral (das 8 h00 às 17h00). 


\section{INSTRUMENTO}

O instrumento utilizado para a coleta de dados foi um questionário com doze questões, que abordavam aspectos sobre a caracterização do participante, estudante PAEE, trabalho docente, família e escola e educação inclusiva.

Para Lüdke e André (1986) o questionário é uma técnica ou instrumento de pesquisa extremamente útil que pode permitir o aprofundamento de pontos levantados pelo investigador.

\section{Resultados e Discussão}

Após a leitura e análise os dados foram organizados em eixos temáticos para melhor analisa-los interpretá-los. Foram identificados quatro eixos temáticos, sendo eles: Concepção acerca da profissão docente; Concepção acerca da inclusão; Auxílio por parte da equipe gestora e Contato com a família.

\section{CONCEPÇÃO ACERCA DA PROFISSÃO DOCENTE}

A profissão docente tem sido objeto de muita investigação nos últimos anos, considerando sua especificidade e complexidade. A inclusão escolar de estudantes PAEE tem intensificado esse debate, uma vez que implica em uma re-conceitualização do trabalho docente e do papel do professor. Nesta perspectiva foi perguntado à professora participante o que significava para ela ser professora, e sua resposta pode ser vista a seguir.

\footnotetext{
Ser Professora foi a realização de um sonho, meus pais foram professores e isso foi sempre um orgulho e um exemplo a ser seguido por nós filhos, eles foram exemplos de professores e pessoas que sonhavam com uma "escola" onde os alunos são os personagens principais e os professores são os atores secundários que apenas davam o caminho a seguir e levava os alunos a criar, a ter o senso de responsabilidade, e olha que isso foi a muito tempo atrás, ver os alunos entrarem de um jeito e saírem de outro ao final do ano não há preşo. Principalmente aquele aluno com maiores dificuldades que com paciência e claro "perseverança" mudam ao longo do ano. Eu só tenho a agradecer a minha profissão que a cada dia me torna uma pessoa melhor.
} 
Diante deste relato, nota-se a sensibilidade da professora em relação à profissão docente, em que em uma concepção construtivista, o aluno deixa de ser passivo e passa ser o protagonista ao lado do professor, tendo este à função de ser o mediador da aprendizagem e não um mero transmissor de conteúdos, pois segundo Becker (2009) a educação deve ser um processo que envolve além de professores e alunos, mas os problemas sociais atuais e o conhecimento por eles já construído.

Ensinar e mediar à aprendizagem tem exigido esforço e dedicação dos professores atuais, onde a diversidade tem se mostrado cada vez mais presente na sala de aula, sendo que no Brasil os professores e demais agentes educacionais ainda possuem uma formação que segue o modelo tradicional de ensino e que não consegue suprir as exigências de um modelo de educação inclusiva. Vale então ressaltar que nos cursos de formação de professores como a Pedagogia e demais licenciaturasl, existe a carência de disciplinas que abrangem conteúdos voltados para alunos com algum tipo de necessidade educacional especial (PLETSCH, M. D. 2009).

Essa carência gera insegurança na atuação do professor, como citado no trecho abaixo, a professora não teve nenhum tipo de preparação para receber o aluno com deficiência em sua turma e mesmo diante do medo causado pela situação nova, precisou realizar pesquisas sem orientação para que pudesse proporcionar o mínimo que o aluno tinha direito.

\section{[...] Eu penso que nada é por acaso, confesso que a principio me deparei com medo e aflição, tudo que é motivo de mudança ou novo, assusta, mas procurei ler sobre o problema do aluno, me inteirar de como se trabalha com uma inclusão e até mesmo procurar um modelo de adaptação curricular, diante das expectativas de ensino aprendizagem do qual minha escola trabalha.}

Esses dados mostram que mesmo diante da falha na formação inicial e continuada a sua concepção sobre a profissão docente, sua preocupação e empenho é evidente, entendendo seu papel e importância na inclusão de alunos com deficiência. No entanto, mostram também a precariedade do processo inclusivo que estamos vivendo, uma vez que a professora buscou alternativas via tentativa e erro, sem embasamento teórico e sem acompanhamento profissional em serviço que proporcionasse tempo e espaço para uma prática reflexiva capaz de auxiliar nas mudanças necessárias. 


\section{CONCEPÇÃO ACERCA DA INCLUSÃO}

Uma das questões do questionário versava sobre a concepção sobre o lugar ideal para escolarização de estudantes PAEE, uma vez que esse paradigma ainda é novo, está em construção, e as opiniões são variadas referente a esta questão. Para esta profissional a escola é o melhor lugar para ocorrer a inclusão, de acordo com Vandercook, Fleetham, Sinclair e Tetlie (1988) é na sala de aula que todas as crianças enriquecem por terem a oportunidade de aprender umas com as outras, com isso elas adquirem valores e atitudes para uma sociedade inclusiva.

\footnotetext{
Eu não vejo problemas em ter aluno de inclusão em sala desde que haja um respaldo por parte da unidade escolar, essa criança necessita de um cuidador e também de viver em uma comunidade atuante como a escola, embora com suas dificuldades ele sempre foi muito bem aceito pela classe, aliás as crianças não trazem com elas o preconceito, elas agem de forma natural e respeitosa, $e$ portanto não vejo necessidade de uma escola diferente.
}

No entanto, proporcionar um ambiente inclusivo não é responsabilidade apenas do professor, mesmo que diante da solidão, eles acabam tomando para si tal responsabilidade, como pode ser visto no seguinte excerto:

De forma geral vejo que não há problemas que eles tenham um ensino comum, desde que a professora se comprometa a procurar "o como trabalhar" com esses alunos, adaptar o curriculo para que ele possa ser assegurado com um minimo de conteúdo daquele ano, ter um olhar ao mesmo tempo que diferenciado, também um olhar normal, mostrando aos outros alunos que não há lugar para o preconceito de forma alguma" (grifo nosso).

Mesmo diante do comprometimento exposto, não é possível ignorar os fatos e seguir, é preciso buscar atitudes da equipe pedagógica, se fundamentar em legislação e ter um aporte teórico, pois a professora não possui apenas esse aluno, mas possui uma classe com dezenas de alunos que precisam da mesma atenção e cuidados.

Mas uma coisa que me incomoda muito é ter um número excessivo de alunos em classe e mais a inclusão, fica sempre a impressão de que poderia ter feito mais, mas o tempo hábil não nos permite. 
Segundo Knüppe (2006) além do professor os alunos também são afetados em salas superlotadas, havendo maior dificuldade no relacionamento com os colegas de classe e com o professor. O professor, por sua vez, sente-se angustiado por não conseguir atender as especificidades de cada aluno, gerando um sentimento de fracasso.

A última frase da professora, onde ela comenta que há "número excessivo de alunos em classe e mais a inclusão" leva a reflexão que esse estereótipo ainda existe, como se o que definisse ele fosse a deficiência. Segundo Beyer (2006), uma escola inclusiva é aquela que não rotula alunos como "normais", "especiais" ou "incluídos", e sim onde há uma pedagogia eficaz perante a cada particularidade de seus alunos.

\section{AUXÍLIO POR PARTE DA EQUIPE GESTORA}

Para que a escola se torne inclusiva a equipe gestora e toda a unidade escolar precisam fazer parte deste processo, fato que se mostrou presente na fala da professora, pois durante todas as respostas nota-se que na escola em que atua há uma equipe gestora preocupada e ativa em relação à inclusão do aluno com deficiência. Quando perguntado se houve alguma providência por parte da equipe gestora para auxiliar seu trabalho a professora respondeu:

Todas, o cuidado de ter uma cuidadora para acompanhar em seus estudos, atividades, lanche, almoço, etc...Também houve o cuidado de se estabelecer regras de horários para entrada e saída do aluno, entre outras coisas.

O gestor escolar que se propõe a atuar numa prática inclusiva envolve-se na organização das reuniões pedagógicas, além de identificar e realizar as adequações curriculares junto aos professores, o que, sem dúvida, é uma colaboração muito importante para que o professor não se sinta sozinho no seu trabalho (VEIGA, L. C. L., 2014). Além do mais, cabe ao gestor tomar as providência administrativas necessárias à implementação do projeto de educação inclusiva.

Embora a participante tenha relato em alguns momentos o isolamento e a procura individual por conhecimento e formas de adaptação, ela mesma relata ações da gestão para auxiliar seu trabalho. Tal realidade mostra as dificuldades da gestão, que também está envolvida em um processo para a qual nem sempre foi preparada, o que 
indica a necessidade de investimento em formação em serviço também para os membros da equipe de gestão escolar como um todo.

\section{CONTATO COM A FAMÍLIA}

A influência familiar é sabidamente um aspecto imprescindível no desenvolvimento educacional de cada um, segundo Buscaglia (1997), a família é uma força social que tem influência na construção do comportamento humano e na formação da personalidade. Sobre este aspecto, a professora relata sobre seu contato e a participação da família:

\footnotetext{
Meu contato foi exatamente como com os outros alunos, apenas tinha mais reuniōes com a mãe para me inteirar dos acontecimentos quanto aos tratamentos, também fotografava todas as atividades relativamente novas que ele conseguia realizar.
}

Mesmo que na fala da professora o contato com a família pareça "normal", ela relatou que essa família é muito compromissada com o aluno. O estudante em questão tem acompanhamento com fonoaudiólogo, fisioterapeuta e psicólogo. São alguns exemplos de suporte providenciado pelos familiares que auxiliam a escola no processo de inclusão. Para Glat (1996), a participação da família tem o poder de ser facilitadora ou impeditiva para que a inclusão aconteça.

\section{Conclusão}

Essa pesquisa buscou investigar como se dá o trabalho pedagógico com alunos público alvo da educação especial na sala de aula comum de uma escola da rede privada de Araraquara (interior de São Paulo) no processo de inclusão escolar.

Após a análise dos dados, foi possível perceber o cuidado da professora no desenvolvimento de um trabalho pedagógico voltado para a inclusão de seus alunos. $\mathrm{Na}$ fala da mesma foi perceptível a preocupação acerca da importância da inclusão na sala regular, ao mesmo tempo em que foi possível verificar que essa atitude é ainda muito mais intuitiva do que profissional, uma vez que a mesma coloca falta de preparo para realizar um trabalho mais assertivo. 
Os resultados apresentaram o quanto é importante uma equipe gestora comprometida com a inclusão, pois facilita o trabalho do professor e agrega para o desenvolvimento do aluno. Porém, apresentaram também a falta de um trabalho estruturado de atendimento educacional especializado, capaz de assessorar de forma efetiva o estudante, bem como, de dar apoio a professora no desenvolvimento do seu trabalho. A simples designação de um cuidador, embora muitas vezes necessária para permanência de alguns estudantes na escola comum, não representa a solução para os entraves pedagógicos que têm que ser assumidos pela professora regular e pela equipe de gestão. Além do professor e da equipe gestora, outro fator importante é a colaboração da família nesse processo. Os dados mostraram que a família em questão está presente na escola e, proporciona atividades complementares para o desenvolvimento do estudante com deficiência.

Os dados encontrados nesta pesquisa, embora com limites por se tratar de um estudo de caso, portanto, obviamente não passível de generalização, permitem inferir o quanto avançamos na inclusão escolar de estudantes PAEE, haja vista a concepção da participante e seu empenho em buscar alternativas que respondam as necessidades do seu aluno, no entanto, mostram também lacunas que precisam ser enfrentadas como formação em serviço para todos os envolvidos no processo educacional, oferecimento de atendimento educacional especializado em escolas da rede privada de ensino, entre tantos outros.

A efetivação de uma escola inclusiva, capaz de oferecer um ensino de qualidade a todos os alunos, requer investimento, participação, formação, enfim, é um processo necessário de reorganização de todo um sistema, para que a garantia de acesso, permanência e sucesso acadêmico seja uma realidade a todos os cidadãos.

\section{Referências}

BECKER, Fernando. O que é construtivismo? Desenvolvimento e Aprendizagem sob o Enfoque da Psicologia II. UFRGS - PEAD 2009/1. Disponível em: < http://maratavarespsictics.pbworks.com/w/file/fetch/74464829/oquee_construtivismo.p df $>$ Acesso em 22 de maio de 2017 
BEYER, H. O. Da integração escolar a educação inclusiva: implicações pedagógicas. In: BAPTISTA, C. (Org.). Inclusão e Escolarização. Porto Alegre: Mediação, 2006.

BIZZI, J. W. J.; MACHADO, A. Mielomeningocele: conceitos básicos e avanços recentes. J Bras Neurocirurg. 23 (2): p.138-151, 2012.

FIGUEIRA, Emílio. Caminhando em silêncio: uma introdução à trajetória das pessoas com deficiência na história do Brasil. São Paulo: Giz Editorial, 2008.

GHIRALDELLI JÚNIOR., Paulo. História da Educação. 2. ed. São Paulo: Cortez, 1991.

GLAT, R. (1996). O papel da família na integração do portador de deficiência. Revista Brasileira de Educação Especial, 2(4), 111-118.

ROCHA, Idnelma Lima da. O ensino fundamental no Brasil - uma análise da efetivação do direito à educação obrigatória. Universidade Federal de Alagoas - Brasil. Disponível em:

<http://www.anpae.org.br/IBERO_AMERICANO_IV/GT1/GT1_Comunicacao/Idn elmaLimadaRocha_GT1_integral.pdf>. Acesso em 23/09/2017.

LEI No 4.024, DE 20 DE DEZEMBRO DE 1961. Disponível em: <http://www.planalto.gov.br/ccivil_03/leis/L4024.htm>. Acesso em 11/06/2017.

LEI No 5.692, DE 11 DE AGOSTO DE 1971. Disponível em: <http://www.planalto.gov.br/ccivil_03/leis/L5692.htm>. Acesso em 11/06/2017.

LEI No 9.394, DE 20 DE DEZEMBRO DE 1996. Disponível em: <http://www.planalto.gov.br/ccivil_03/leis/L9394.htm>. Acesso em 11/06/2017.

LEI No 12.796, DE 4 DE ABRIL DE 2013. Disponível em:< http://www.planalto.gov.br/ccivil_03/_Ato20112014/2013/Lei/L12796.htm\#art1> Acesso em 29/04/2017

MEC/SECADI Politica Nacional de Educação Especial na Perspectiva da Educação Inclusiva. Disponível em:

$<$ http://portal.mec.gov.br/index.php?option=com_docman\&view=download\&alias=166 
SOUZA, T. A. de; CANDIDO, E. A. P.; CARNEIRO, R. U. C. Educação inclusiva: um estudo de caso sobre o trabalho docente no Ensino Fundamental I. R. Cientifica UBM - Barra Mansa (RJ), ano XXII, v. 19, n. 37, 2. Sem. 2017. p. 211-224. ISSN 1516-4071

90-politica-nacional-de-educacao-especial-na-perspectiva-da-educacao-inclusiva05122014\&Itemid=30192>. Acesso em 29/04/2017

LUDKE, M.; ANDRE, M. Pesquisa em Educação: Abordagens qualitativas. São Paulo: E.P.U., 1986.

PLETSCH, M. D. A formação de professores para a educação inclusiva: legislação, diretrizes políticas e resultados de pesquisas. Educar, Curitiba, n. 33, p. 143-156, 2009. Editora UFPR.

STAKE, R. E. The art of case study research. SAGE Publications, 1995.

VEIGA, L. C. L. O papel do gestor escolar no processo de inclusão de alunos com necessidades educativas especiais. Universidade de Brasília. Brasília (DF), Julho de 2014. 